\title{
COMPARISON OF INTRAVENOUS AND RECTAL PARACETAMOL FOR PAIN RELIEF IN CHILDREN UNDERGOING TONSILLECTOMY SURGERY
}

\author{
Pachaimuthu Elango ${ }^{1}$, Vivekanandan Balasubramaniaguhan ${ }^{2}$, Gurusamy Sivakumar ${ }^{3}$, Krishnamurthi Anitha $^{4}$, Anbu Srinivasan ${ }^{5}$ \\ ${ }_{1}^{1}$ Associate Professor, Department of Anaesthesiology, KAP Viswanatham Government Medical College/MGM Govt. Hospital, Trichy. \\ ${ }^{2}$ Assistant Professor, Department of Anaesthesiology, KAP Viswanatham Government Medical College/MGM Govt. Hospital, Trichy. \\ 3 Professor, Department of Anaesthesiology, KAP Viswanatham Government Medical College/MGM Govt. Hospital, Trichy. \\ ${ }^{4}$ Assistant Professor, Department of Anaesthesiology, KAP Viswanatham Government Medical College/MGM Govt. Hospital, Trichy. \\ ${ }^{5}$ Associate Professor, Department of Orthopaedics, KAP Viswanatham Government Medical College/MGM Govt. Hospital, Trichy.
}

\section{ABSTRACT}

\section{BACKGROUND}

Children undergoing Tonsillectomy have significant pain. Various modalities of treatment have been used to treat pain. Our aim is to compare the duration of analgesia and comfort of child with paracetamol administered through intravenous and rectal route.

\section{MATERIALS AND METHODS}

40 children undergoing tonsillectomy surgeries were randomised into two groups receiving either intravenous paracetamol (Group I) or rectal paracetamol (Group R) as suppositories. After induction and intubation, children were randomised to one of the groups. Haemodynamic parameters were recorded preop; intraop and post-operatively along with assessment of post-operative pain using Wong-Baker face pain scale for period of 10 hours. Kruskal-Wallis chi-square test was used to test the significance of difference between quantitative variables and Yate's chi square test for qualitative variables.

\section{RESULTS}

Thus, duration of analgesia was significantly ( $\mathrm{p}=0.0029)$ higher in rectal group than in IV group. Comfort scores were not statistically significant.

\section{CONCLUSION}

The post-operative pain scores were significantly higher in the intravenous group as compared to the rectal group. There was no difference in post-operative comfort.

\section{KEYWORDS}

Intravenous and Rectal Paracetamol, Tonsillectomy.

HOW TO CITE THIS ARTICLE: Elango P, Balasubramaniaguhan V, Sivakumar G, et al. Comparison of intravenous and rectal paracetamol for pain relief in children undergoing tonsillectomy surgery. J. Evolution Med. Dent. Sci. 2017;6(34):2845-2848, DOI: $10.14260 /$ Jemds/2017/611

\section{BACKGROUND}

Tonsillectomy is one of the frequently performed surgeries in children. It is associated with significant post-operative pain that results in post-operative nausea and vomiting, ${ }^{1}$ poor oral intake and lassitude. The reported incidence of pain is $25 \%$ $50 \%^{2}$ in children. Various strategies have been used to treat this pain like intraoperative infiltrations with local anaesthetics to post-operative opioids and NSAIDs. Respiratory depression, nausea, vomiting and sedation from opioids after tonsillectomy may be hazardous where prompt return of airway reflex is anticipated. NSAIDs are equianalgesic with opioids for tonsillectomy, but there are concerns that it increases the chances of post-operative bleeding. ${ }^{3}$ Paracetamol (Acetaminophen) is an analgesic and antipyretic with little antiinflammatory effect. It acts at both central and peripheral components of pain pathway ${ }^{4}$ by direct inhibition of the NMDA receptor that stimulates the substance $P$

Financial or Other, Competing Interest: None.

Submission 24-02-2017, Peer Review 14-04-2017,

Acceptance 20-04-2017, Published 27-04-2017.

Corresponding Author:

Dr. Vivekanandan Balasubramaniaguhan,

\#4E/20, Anandham En Shrine,

Raja Colony, Second Street,

Cantonment, Trichy-620001.

E-mail: drbalaguhan@yahoo.co.in

DOI: $10.14260 /$ jemds $/ 2017 / 611$

dependent synthesis of nitric oxide, a primary mediator of nociception. ${ }^{5}$ It is also believed to inhibit the cyclooxygenase 2 pathway involved in prostaglandin synthesis. The analgesic effects may also involve the serotogenic system. ${ }^{6}$ It is the most widely used drug for pain relief. In order of increasing effectiveness, paracetamol can be administered rectally, orally and intravenously. While all three modes of administration can achieve adequate plasma concentrations, there are differences in absorption and time to reach peak plasma levels. ${ }^{7}$ Paracetamol, at therapeutic doses, rarely results in adverse effects. Oral administration of paracetamol is limited by pain during swallowing, post-operative nausea and vomiting. Not all patients accept rectal administration of paracetamol and is associated with erratic plasma concentration and may or may not achieve desired therapeutic levels. Intravenous paracetamol is associated with predictable plasma concentration. The objective of this study is to compare the clinical efficacy of intravenous paracetamol with rectal paracetamol in children undergoing tonsillectomy operation and post-operative comfort in the next 24 hours.

\section{MATERIALS AND METHODS}

After approval by the Institutional Ethical Committee, informed written consent was obtained from the parents of 40 children with American Society of Anaesthesiologists physical status I and $\Pi$, aged 5 - 12 years, weighing less than $30 \mathrm{~kg}$, undergoing elective tonsillectomy. The sample was 
estimated to be 50 in each group. According to a study by Capici $\mathrm{F}$ et al the mean (SD) wake-up time was found to be $18^{(8)}$ in per rectal group and $14(6)$ in intravenous group with an allocation ratio of 1 , Alpha $=0.05$ and Beta $=0.20$. Finally, a total of 120 patients were included, 60 in each group. Study was conducted over a period of 3 months at Thanjavur Medical College. Children with renal impairment, liver disease intolerance to NSAIDs, a history of PONV, motion sickness and rectal bleeding were excluded. After routine investigation like complete haemogram, blood grouping and typing, bleeding time and clotting time all children were fasted for 6 hours for solid food before the procedure. Children were randomly allocated in two groups. Group I: Receiving paracetamol intravenously $15 \mathrm{mg} / \mathrm{kg}$ (Anemol 10 $\mathrm{mg} / \mathrm{mL}$, Themis Medicare Ltd.) and Group R: Receiving paracetamol rectally $40 \mathrm{mg} / \mathrm{kg}$. (Neomol $250 \mathrm{mg}$ suppositories, Neon Laboratories, India).

Children in both groups were preoxygenated for 3 minutes, connected to routine monitors. Both groups received midazolam $0.05 \mathrm{mg} / \mathrm{kg}$ and glycopyrrolate $10 \mu \mathrm{g} / \mathrm{kg}$ intravenously with maximum dose of $0.2 \mathrm{mg}$ before induction as premedication. Anaesthesia was induced with Propofol 2 $\mathrm{mg} / \mathrm{kg}$ and fentanyl $2 \mu \mathrm{g} / \mathrm{kg}$. Succinylcholine $2 \mathrm{mg} / \mathrm{kg}$ was given to facilitate endotracheal intubation. Anaesthesia was maintained with sevoflurane $2 \%-2.5 \%$ in oxygen/nitrous oxide mixture and atracurium was used for muscle relaxation. Blood Pressure (BP), Heart Rate (HR), Respiratory Rate (RR) and oxygen saturation were continuously monitored. After intubation, patients received paracetamol either intravenously $15 \mathrm{mg} / \mathrm{kg}$ (Group I) or rectally $40 \mathrm{mg} / \mathrm{kg}$ (Group R). After the end of surgery, neuromuscular block was reversed with neostigmine $40 \mu \mathrm{g} / \mathrm{kg}$ and glycopyrrolate 10 $\mu \mathrm{g} / \mathrm{kg}$. Patients were transferred to the recovery room. HR, systolic arterial BP, RR and oxygen saturation were monitored continuously. Pain intensity was recorded by observer who has no knowledge of method of pain relief in the patient. Post-operative pain assessment was done using Wong-Baker Faces Pain Scale every 15 mins. for the first hour, followed by every 2 hours for the next hours. The time to first rescue analgesia was defined as the time from tracheal extubation to the indication for supplemental analgesia when the Wong-Baker Faces Pain Score was greater than or equal to 6 . Rescue analgesia was provided with pentazocine 0.6 $\mathrm{mg} / \mathrm{kg}$ IV. The child's comfort in the post-operative ward was assessed after 24 hours using a previously described scale designed to assess recovery after tonsillectomy. The scale comprised of five separate measures, each of which was assigned a score and the score then summed-

1. Spontaneous pain (0-no pain, 1- mild, 2- moderate, 3severe).

2. Pain at swallowing (0- no pain, 1- mild, 2- moderate, 3severe).

3. Occurrence of PONV (0 or 1$)$.

4. Disturbed feeding ( 0 or 1$)$.

5. Disturbed sleep (0 or 1$)$.

A total score of 3 or less points was considered as very satisfactory. As a secondary outcome, we measured behaviour of the children after operation was evaluated using a four-point agitation scale-

1. Calm child requiring no intervention.
2. Consolable child requiring only physical contact with the parent.

3. Agitated, screaming and crying child.

4. Aggressive child, requiring physical restrainment in order to avoid harm.

We defined significant post-operative agitation as an agitation scale of 3 or 4 . Pain intensity was assessed every 15 minutes in the recovery room till Aldrete score of 8 and every 2 hours during the first 10 hours in the post-operative ward. Post-operative pain assessment was done by an observer blinded to the study. Kruskal-Wallis chi-square test was used to test the significance of difference between quantitative variables and Yate's chi square test for qualitative variables. A ' $p$ ' value less than 0.05 is taken to denote significant relationship.

\section{RESULTS}

All the patients enrolled in the study received the treatment according to the group they were randomly allocated and completed the study. The study groups were comparable in term of gender, weight, duration of surgery and dose of fentanyl used (Table 1).

\begin{tabular}{|c|c|c|}
\hline $\begin{array}{c}\text { Gender and } \\
\text { Weight }\end{array}$ & Group I & Group R \\
\hline Male n (\%) & $9(45)$ & $11(55)$ \\
\hline Female n (\%) & $11(55)$ & $9(45)$ \\
\hline Weight Mean SD & $23(5.3)$ & $23.2(5.4)$ \\
\hline \multicolumn{2}{|c|}{ Table 1. Gender and Weight of Patients } \\
\hline
\end{tabular}

\begin{tabular}{|c|c|c|c|}
\hline & Group I & Group R & P \\
\hline $\begin{array}{c}\text { Duration of } \\
\text { Surgery (mins) }\end{array}$ & $34.3 \pm 5.3$ & $33.7 \pm 5.5$ & 0.85 \\
\hline $\begin{array}{c}\text { Dose of Fentanyl } \\
(\mu \mathrm{g})\end{array}$ & $45.9 \pm 10.5$ & $46.5 \pm 10.8$ & 0.88 \\
\hline \multicolumn{3}{|c|}{ Table 2. Duration of Surgery and Dose of Fentanyl } \\
\hline
\end{tabular}

\begin{tabular}{|c|c|c|c|}
\hline \multirow{2}{*}{$\begin{array}{c}\text { Wong-Baker } \\
\text { Pain Score at }\end{array}$} & $\begin{array}{c}\text { Value for ( Mean } \pm \text { SD) } \\
\text { Rectal } \\
\text { Group }\end{array}$ & $\begin{array}{c}\text { IV } \\
\text { Group }\end{array}$ & \multirow{2}{*}{ 'p' } \\
\hline 15 minutes & 0 & 0 & - \\
\hline 30 minutes & 0 & 0 & - \\
\hline 45 minutes & 0 & 0 & - \\
\hline 60 minutes & 0 & 0 & - \\
\hline 2 hours & $1.5 \pm 0.9$ & $1.9 \pm 1.0$ & 0.21 Not significant \\
\hline 4 hours & $2.8 \pm 1.0$ & $3.4 \pm 1.1$ & $\begin{array}{c}0.0956 \text { Not } \\
\text { significant }\end{array}$ \\
\hline 6 hours & $4.3 \pm 0.7$ & $4.5 \pm 1.3$ & $\begin{array}{c}0.4373 \text { Not } \\
\text { significant }\end{array}$ \\
\hline 8 hours & $4.2 \pm 0.6$ & $5.7 \pm 0.7$ & 0.0001 Significant \\
\hline 10 hours & $5.5 \pm 0.9$ & $6.0 \pm 0$ & 0.0183 Significant \\
\hline Table 3. Wong-Baker Pain Score at various Time Intervals \\
\hline
\end{tabular}

Wong-Baker pain score was significantly higher in IV group at 8 hours and 10 hours (Table 3). Before that there was no significant difference in Wong-Baker pain score at 2,4 and 6 hours. Time for first rescue analgesia was $552 \pm 99.4$ minutes in rectal route and $450 \pm 94.4$ minutes in IV route (Fig. 1). Thus duration of analgesia was significantly $(p=0.0029)$ higher in rectal group than in IV group. The 
comfort score after 24 hours was less than three in both groups and is not significant (Fig. 2). Even though paracetamol was given either by rectal or intravenous route reduced the score with regard to disturbed sleep, disturbed feeding and post-operative vomiting the score remains high in both groups with respect to pain on swallowing.

\begin{tabular}{|c|c|c|c|c|}
\hline $\begin{array}{c}\text { Scale of Post- } \\
\text { Operative Agitation }\end{array}$ & \multicolumn{2}{|c|}{ Rectal Group } & \multicolumn{2}{c|}{ IV Group } \\
\cline { 2 - 5 } & No & $\mathbf{\%}$ & No & $\mathbf{\%}$ \\
\hline 1 & 2 & 10 & 5 & 25 \\
\hline 2 & 10 & 50 & 5 & 25 \\
\hline 3 & 6 & 30 & 10 & 50 \\
\hline 4 & 2 & 10 & - & - \\
\hline Total & $\mathbf{2 0}$ & $\mathbf{1 0 0}$ & $\mathbf{2 0}$ & $\mathbf{1 0 0}$ \\
\hline $\begin{array}{c}\text { Significant Agitation } \\
\text { (3 or 4) }\end{array}$ & 8 & 40 & 10 & 50 \\
\hline $\mathrm{p}$ & \multicolumn{3}{|c|}{0.7506 Not Significant } \\
\hline \multicolumn{4}{|c|}{ Table 4. Post-Operative Agitation } \\
\hline
\end{tabular}

Significant post-operative agitation was present in 8 out of 20 cases (40\%) was given paracetamol in rectal route and in 10 out of 40 cases $(50 \%)$ given paracetamol in IV route. This difference was not statistically significant $(p>0.05)$.

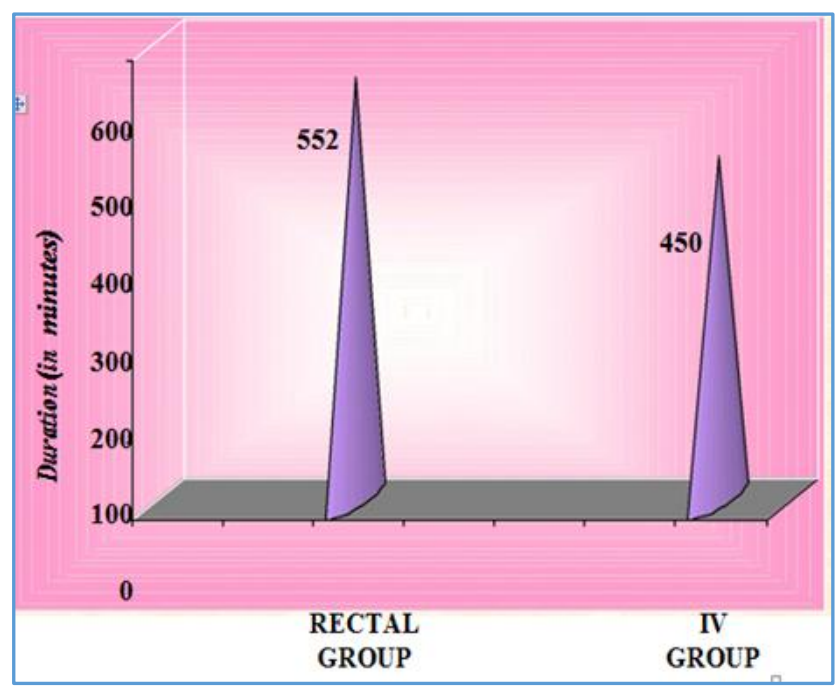

Figure 1. Duration of Analgesia

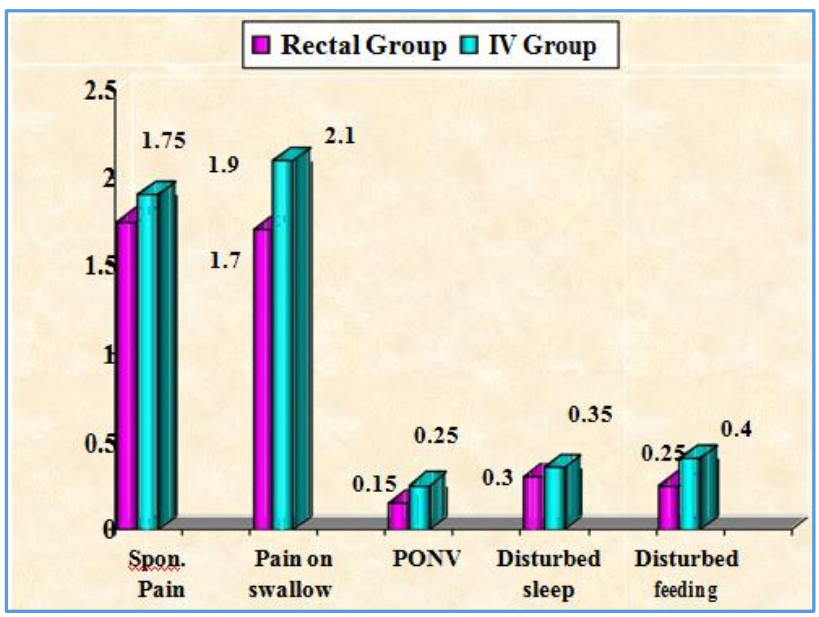

Figure 2. Comfort Scale after 24 Hours

\section{DISCUSSION}

Our study demonstrates that rectal paracetamol has prolonged analgesic efficacy over intravenous paracetamol. We used $40 \mathrm{mg} / \mathrm{kg}$ rectally as single dose. There are studies where the dosage commonly used is $10-15 \mathrm{mg} / \mathrm{kg}$ four times a day or single bolus dose. Study by Korpela R concluded that single dose of 40 or $60 \mathrm{mg} / \mathrm{kg}$ of rectal acetaminophen has a clear morphine-sparing effect in day-case surgery in children if administered at the induction of anaesthesia and the ED of rectal paracetamol is $35 \mathrm{mg} / \mathrm{kg}$. Birmingham $\mathrm{PK}$ et al ${ }^{8}$ in their study suggested an initial dose of $40 \mathrm{mg} / \mathrm{kg}$ of rectal paracetamol. A higher loading dose $(45 \mathrm{mg} / \mathrm{kg})$ was not associated with a significantly greater risk of overdose, as the highest plasma concentration measured was $25 \mu \mathrm{g} / \mathrm{mL}$, substantially less than the accepted toxic concentration of $120 \mu \mathrm{g} / \mathrm{mL}$. Intravenous paracetamol follows first order kinetics, reaches peak concentration within 15 mins. When propacetamol administered in a dose of $40 \mathrm{mg} / \mathrm{kg}$ and 20 $\mathrm{mg} / \mathrm{kg}$ intravenous was found to have concentration of 56 $\mathrm{mg} / \mathrm{L}$ and $28 \mathrm{mg} / \mathrm{L}$ respectively. One gram of propacetamol is hydrolysed to $0.5 \mathrm{~g}$ acetaminophen. The pharmacokinetics of intravenous acetaminophen have been described in several studies and the serum therapeutic level required to produce an analgesic effect is $16 \mathrm{mcg} / \mathrm{mL}$ in adults and $10 \mathrm{mcg} / \mathrm{mL}$ in children. Studies by Tian J. Zhou and Hugo Van Aken and Thys concluded that intravenous propacetamol provide pain relief up to 5 hours. In our study, intravenous paracetamol provided pain relief up to 6 hours. The study by Renuka Kulkarni and Nandhini Dave ${ }^{9}$ on rectal paracetamol in children undergoing minor surgery observed that there is no need for rescue medication up to 6 hours. Dose of paracetamol used in this study was $30 \mathrm{mg} / \mathrm{kg}$. Study by Ranju Gandhi and Rani Sunder ${ }^{10}$ concluded that single dose rectal acetaminophen can provide effective post-operative analgesia for paediatric ophthalmic surgery at both doses high $(40 \mathrm{mg} / \mathrm{kg})$ and low $(20 \mathrm{mg} / \mathrm{kg})$ both in the early postoperative and over a 24 -hour period. The mean time to requirement of first analgesic was $206 \pm 185$ mins in their study. In our study, rectal paracetamol provided significant pain relief till 10 hours and the dose was $40 \mathrm{mg} / \mathrm{kg}$. Our study results were in line with study by Capici F,11 in which the post-operative pain was assessed by the Children and Infants. Post-operative Pain Scale score with median time to rescue analgesia was 10 hours. Contrary to our finding, the study by Prins SA and Van Dijk ${ }^{12}$ suggested that intravenous propacetamol in infants for craniofacial surgery was more effective than rectal paracetamol. This may be due to varying analgesic requirement with different surgeries, concurrent use of other analgesic agents and the absorption of rectal paracetamol itself is erratic and irregular. Further, the variability in the rate and extent of absorption of suppositories is thought to be due to several factors like the volume of the suppository, the number of suppositories used and the particle size of the paracetamol. Bioavailability of rectal paracetamol is variable and is between $24 \%-98 \%{ }^{13}$ Time taken to achieve maximum plasma concentration is about 2 - 3 hrs. after administration. Lipophilic bases provide greater bioavailability than hydrophilic base. This factor is to be considered while timing the administration of the drug rectally. Children also absorb rectal paracetamol faster because of limited space available in rectum resulting in better contact of rectal mucosa with suppositories. ${ }^{13}$ In our 
study, we used only $250 \mathrm{mg}$ suppositories. Rectal $\mathrm{pH}$ may also influence the absorption of paracetamol by altering the degree of dissociation and therefore the ability of the drug to pass through biological membranes. ${ }^{7}$ In children, rectal $\mathrm{pH}$ can vary from 7.8 - 11.4 and in this range the degree of dissociation of paracetamol will vary from $2 \%-99 \% .^{14}$ The placement of the suppository in the rectum is equally important in determining the serum concentrations achieved, due to the variability of the venous drainage from the rectum. If the suppository were placed in the upper part of the rectum, the drug would be absorbed into the portal circulation and would undergo hepatic first-pass metabolism, whereas if it were placed in the lower part of the rectum it would bypass the liver and directly absorbed into the systematic circulation. Although, the placement of the suppository was kept constant during the study, it is difficult in the children to exactly differentiate between the upper $1 / 3^{\text {rd }}$ and lower $2 / 3^{\text {rd }}$ of the rectum and hence it is possible that in some of the children, especially in the younger ones there was a variation in placing the suppository resulting in differences in absorption, metabolism and hence drug levels. ${ }^{15}$ Further variation in pain score and plasma levels were seen even with opioids after standard dose was administered. Thus, even though intravenous paracetamol seems better in terms of pharmacokinetics profile studies have shown that differences in plasma exposure between routes of administration may not necessarily result in differences in clinical outcomes. ${ }^{16}$ Limitation in our study was plasma levels of the drug were not measured at corresponding pain score level. We used only single dose of rectal paracetamol for post-operative pain, as tonsillectomy results only in mild-to-moderate pain relief and is unnecessary leading to physical discomfort. Also it is difficult to assess pain in children due to differences in cognition and communication skills along with different cultural and social learning. ${ }^{15}$ Thus, effective analgesia for longer duration by rectal administration of paracetamol in spite of varying bioavailability was presumed due to effect-site concentration persisting for longer duration because of above mentioned factors.

\section{CONCLUSION}

We conclude that rectal paracetamol has prolonged analgesic efficacy than intravenous paracetamol in children in posttonsillectomy pain with no difference in post-operative comfort.

\section{REFERENCES}

[1] White MC, Nolan JA. An evaluation of pain and postoperative nausea and vomiting following the introduction of guidelines for tonsillectomy. Paediatr Anaesth 2005;15(8):683-8.

[2] Kotiniemi LH, Ryhanen PT, Valanne J, et al. Postoperative symptoms at home following day-case surgery in children: a multicentre survey of 551 children. Anaesthesia 1997;52(10):963-9.
[3] Moiniche S, Romsing J, Dahl JB, et al. Nonsteroidal antiinflammatory drugs and the risk of operative site bleeding after tonsillectomy: a quantitative systematic review. Anesth Analg 2003;96(1):68-77.

[4] Aken VH, Thys L, Veekman L, et al. Assessing analgesia in single and repeated administration of propacetamol for postoperative pain: comparison with morphine after dental surgery. Anesth Analg 2004;98(1):159-65.

[5] Zhou TJ, Tang J, White PF. Propacetamol versus ketorolac for treatment of acute postoperative pain after total hip or knee replacement. Anesth Analg 2001;92(6):1569-75.

[6] Bjorkman R, Hallman KM, Hedner J, et al. Acetaminophen blocks spinal hyperalgesia induced by NMDA and substances P. Pain 1994;57(3):259-64.

[7] Oscier M, Bosley B, Milner S. Paracetamol: a review of three routes of administration. Update in Anaesthesia 2007;23:112-4.

[8] Birmingham PK, Tobin MJ, Fisher DM, et al. Initial and subsequent dosing of rectal acetaminophen in children: a 24-hour pharmacokinetic study of new dose recommendations. Anesthesiology 2001;94(3):385-9.

[9] Kulkarni R, Dave N, Bartakke A, et al. Pharmacokinetics of rectal compared to intramuscular paracetamol in children undergoing minor surgery. Indian Journal of Pharmacology 2007;39(4):187-91.

[10] Gandhi R, Sunder R. Postoperative analgesic efficacy of single high dose and low dose rectal acetaminophen in pediatric ophthalmic surgery. J Anaesthesiol Clin Pharmacol 2012;28(4):460-4.

[11] Capici F, Ingelmo PM, Davidson A, et al. Randomized controlled trial of duration of analgesia following intravenous or rectal acetaminophen after adenotonsillectomy in children. $\mathrm{Br} \mathrm{J}$ Anaesth 2008;100(2):251-5.

[12] Prins SA, Dijk VM, Leeuwen VP, et al. Pharmacokinetics analgesic effects of intravenous propacetamol vs rectal paracetamol in children after major craniofacial surgery. Pediatr Anesth 2008;18(7):582-92.

[13] Hahn TW, Henneberg SW, Holm-Knudsen RJ, et al. Pharmacokinetics of rectal paracetamol after repeated dosing in children. Br J Anaesth 2000;85(4):512-9.

[14] Alternative routes of drug administration--advantages and disadvantages (subject review). American academy of paediatrics. Committee on drugs. Pediatrics 1997;100(1):143-52.

[15] Srouji R, Ratnapalan S, Schneeweiss S. Pain in children: assessment and non-pharmacological management. International Journal of Pediatrics 2010:Article ID 474838:11.

[16] Jibril F, Sharaby S, Mohamed A, et al. Intravenous versus oral acetaminophen for pain: systematic review of current evidence to support clinical decisionmaking. Can J Hosp Pharm 2015;68(3):238-47. 